\title{
O espaço múltiplo da colonização agrária: um livro pioneiro e suas novas perspectivas
}

\author{
KOHLHEPP, Gerd. Colonização agrária no Norte do Paraná: processos \\ geoeconômicos e sociogeográficos de desenvolvimento de uma zona tropical \\ periférica do Brasil sob a influência da plantação de café (Org. Paulo Soethe). \\ Trad. (Org.) Daniel Marineschen. Maringá: EDUEM, 2014, 310p. [com 15 figuras, \\ 16 fotos, 59 mapas e 45 tabelas]
}

Wolf-Dietrich Sahr

Departamento de Geografia da Universidade Federal do Paraná (Ufpr)

O livro "Colonização agrária no Norte do Paraná", de autoria do Prof. Dr. Gerd Kohlhepp, da Universidade alemã de Tübingen, agora se encontra acessível em tradução portuguesa. O livro representa um marco importante nas reflexões sobre o Brasil dos anos 1970, época na qual o país se encontrou em plena mudança social. Publicada originalmente no ano de 1975, como volume 41 dos "Trabalhos Geográficos de Heidelberg", a detalhadíssima pesquisa relata e interpreta as transformações do sistema agrário, utilizando o exemplo da cafeicultura do norte paranaense, no auge da ditadura militar. Nessa perspectiva, reúne observações econômicas e sociais, acrescentadas por observações ecológicas. Tal combinação é relativamente rara no ambiente científico, devido à crescente segmentação das áreas acadêmicas especializadas. Uma equipe de oito acadêmicos, sob a coordenação do Prof. Dr. Paulo Soethe, do Departamento de Letras, da Universidade Federal do Paraná, tem o grande mérito na tradução do livro, que contou com o apoio da Fundação Baden-Württemberg e da Editora da Universidade Estadual de Maringá. Já em 1972, a pesquisa foi apresentada, pela primeira vez, como Tese de Livre Docência na Universidade de Heidelberg.

No seu conteúdo, o livro - o primeiro que acompanhou em detalhe o processo da colonização no norte do Paraná - revela um interessante encontro de diversas correntes acadêmicas, da mesma forma como a região investigada aparece na época como encontro de diferentes correntes migratórias socioeconômicas e étnicas. Entre os anos 1930 e 1975, o Brasil passou por profundas mudanças sociais e econômicas - mudanças que adquirem feições diferenciadas, dependendo do ângulo e da escala da perspectiva. Consequentemente, o livro se divide em sete 
partes. Inicia-se com uma descrição e interpretação das condições ambientais do Norte Paranaense. Em seguida, contextualiza o povoamento da área dentro das políticas populacionais e econômicas do Brasil desde o século XVI. Depois apresenta o avanço do café na economia brasileira e no Norte do Paraná, integrando esta situação ao desenvolvimento do mercado mundial dos anos 1960 e 1970. Na sequência, avalia as intervenções de um Estado autoritário com relação ao café, como também as consequências das repetidas geadas durante os anos 1960 (a pesquisa foi originalmente publicada antes da grande geada de 1975). Finalmente, chega à análise das políticas de diversificação no Brasil e da reorganização do mercado mundial sob a égide dos E.U.A.

O trabalho do Prof. Dr. G. Kohlhepp enquadra-se entre as várias pesquisas de brasilianistas alemães, os quais representam uma ampla tradição empírica. Tendo sido formado no Departamento de Geografia, da Universidade de Heidelberg, Gerd Kohlhepp tornou-se professor assistente e doutorando sob orientação do prof. Dr. Gottfried Pfeiffer, um reconhecido especialista em pesquisas sobre a América Latina, principalmente nos anos 1950 e 1960. Entre outros, Pfeiffer participou da comissão científica que buscou determinar a localização da então futura capital do Brasil no Planalto Central. O Departamento de Geografia da Universidade de Heidelberg foi onde Alfred Hettner ocupou uma cátedra em Geografia, o mesmo Alfred Hettner que visitou o Rio Grande do Sul no momento da revolução da Velha República. Um dos alunos de Hettner, o notório prof. Dr. Leo Waibel - orientador de Pfeiffer - passou entre 1946-1950 no Brasil, pesquisando questões da Geografia Agrária e da colonização no Sul do Brasil. O seu conceito de "Formação Econômica" (melhor: "Formação socioeconômica"), o qual foi desenvolvido no Sul do México, destaca o contraste entre fazendas e produção campesina, uma diferenciação que, mesmo operando com outros atores socioeconômicos, tem claros reflexos na descrição da sociedade agrária paranaense no livro.

Além destes pesquisadores alemães, o trabalho considera também pesquisadores franceses da época, principalmente Pierre Monbeig, e suas investigações sobre as frentes agrárias no estado de São Paulo. Ao contrário dos professores brasilianistas alemães, o grupo de geógrafos franceses no Brasil mostra até hoje mais envolvimento institucional no país. Diante desta diferença, pesquisas alemãs geralmente se orientam mais numa interpretação "apenas" científica, e assim são menos partidárias frente às profundas divisões da sociedade brasileira. Isto garante certa multiperspectividade e proximidade para com diversos grupos sociais - uma característica que se percebe claramente também nesta obra de Kohlhepp.

Em relação aos campos epistemológicos do trabalho, vale à pena mencionar alguns aspectos importantes. Através da interação de Leo Waibel e Gottfried Pfeiffer com geógrafos norte-americanos, as teorias de "frente pioneira" (Turner, Bowman, James) recebem um destaque na obra com relação à configuração do espaço socioagrário. Aqui, a investigação torna-se bastante pormenorizada, 
diferenciando fluxos ecológicos, de capital e relações sociais e fundiárias, que se articulam em uma visão holística. Observa-se, por exemplo, que o processo de colonização da região mobiliza diferentes grupos sociais, em diferentes formas, nomeadamente latifundiários paulistas; descendentes do colonato italiano e grupos de imigrantes japoneses de São Paulo; trabalhadores rurais originários, em grande parte, de Minas Gerais, Bahia e Pernambuco; e, por fim, principalmente, a partir de 1967, trabalhadores volantes (boias frias), tanto de origem nordestina como também descendentes de caboclos do Centro-Sul do Brasil.

Revela-se, nesta perspectiva, que a negociação das relações entre proprietários, empresários, trabalhadores, sociedade e Estado no Brasil resulta numa enorme flexibilização das relações sociais e suas interações. Consequentemente, o trabalho aponta de que forma estas relações se intensificam ou se desfazem diante das conjunturas políticas e econômicas. Tal maleabilidade, de certa forma típica para a conformação da sociedade brasileira, aparece sob diferentes ângulos em vários estudos de caso, além de observações gerais. Denominamos, especificamente, o caso da região de Rolândia, onde o autor morou durante sua pesquisa de campo; o caso do grupo socioétnico de japoneses, inclusive a cooperativa COTIA; ou as entrevistas que o autor fez com trabalhadores rurais em várias regiões, cujas relações os transformaram de trabalhadores rurais em empregados precários, como boias frias.

Os conceitos de mobilidade social e de mobilidade espacial, originalmente, propostos pelo sociólogo P. Sorokin e aplicados na renomada escola sociológica de René König (Universidade de Colônia), permitem não apenas a diferenciação flexível de grupos socioeconômicos de acordo com renda, força produtiva e status, mas também a interligação dessas mudanças com movimentos geográficos, como migração, colonização e/ou expulsão. Assim, a pesquisa consegue demonstrar, de forma empírica e sustentada por dados estatísticos e qualitativos, diferentes momentos entre os grupos e classes sociais. De maneira que os trabalhadores rurais da época não alcançam um grau de capitalização suficiente para o próprio sustento, o que permitiria modificações na precária situação vivenciada pelos mesmos. Ao contrário, a classe média, em grande parte surgida do colonato italiano de São Paulo, é fortemente mobilizada através de uma ascensão social na frente pioneira. Contudo, membros da classe alta ativa na frente não mudaram seu status social.

Um ponto interessante é que as observações de Kohlhepp se fazem principalmente com base em concepções desenvolvidas por geógrafos brasileiros, entre eles os do IBGE, mas também por membros do departamento de Geografia da UFRJ, como Orlando Valverde, Lysia e Nilo Bernardes e Maria do Carmo Corrêa Galvão. Chama atenção que as concepções vigentes na Geografia Agrária e Rural brasileira de hoje, as quais se referem predominantemente a concepções neomarxistas de autores como Florestan Fernandes ou José de Souza Martins, obviamente, não se encontram no trabalho de Kohlhepp. Contudo, elas aparecem 
de forma velada em figuras como o 'ocupante', 'arrendatário' ou 'colono' (pequeno proprietário). Parece que a abordagem da mobilidade social e de grupos socioeconômicos serve melhor à compreensão de mudanças, enquanto a abordagem de classes se refere mais a situações estáveis.

Não ter aplicado abordagens marxistas, contudo, não significa que Gerd Kohlhepp não criticasse o funcionamento do capitalismo. Pelo contrário. Todavia, sua maior crítica (esta também não tão aberta devido à ditadura militar) dirige-se às intervenções do Estado dentro do processo social. Assim, ele demonstra como o estabelecimento do salário mínimo para o trabalhador rural resultou, na época, não numa melhora na condição dessas pessoas, mas, ao contrário, numa crescente flexibilização e terceirização das relações de trabalho, trazendo mais precariedade à população rural de baixa renda. Esta se vê forçada a buscar uma diversificação de suas fontes de renda nas periferias das cidades, principalmente, quando a cafeicultura entra em crise - e isto num momento em que os problemas no mercado mundial e as geadas aumentam.

Esta observação, com validade até hoje, necessita - a meu ver - ainda de um amplo debate entre geógrafos, sociólogos, economistas e estudiosos do desenvolvimento regional. Podemos tirar como lição que vários conceitos de desenvolvimento são apenas baseados na expansão do sistema econômico capitalista (como até recentemente muitas políticas, tanto da esquerda como da direita, no Brasil), enquanto os reais efeitos e a sustentabilidade de tais medidas se revelam, em sua plenitude, apenas em fase de crise e de encolhimento. A pesquisa mostra isso com muita clareza e de forma exemplar, por basear-se em métodos científicos, sem nenhuma alusão partidária.

Neste sentido, destacamos também a forma como o livro contextualiza as políticas públicas do Brasil na época, enquadradas no mercado mundial de café como condicionante do processo de colonização. Neste momento, o Brasil representava $50 \%$ deste mercado, exportando grande parcela de sua produção aos E.U.A. Naquele mercado o governo encontrou-se entre dois problemas contraditórios: de um lado, tinha que promover a expansão da exportação do café para ganhar divisas, mas, de outro, se via obrigado a estabilizar os preços do mesmo mercado através de uma política de redução da produção. Acrescenta-se a essa situação a falta de previsibilidade em função de problemas ecológicos, como as geadas. De certa forma, as oscilações entre ambas as intenções criaram profundas incertezas no cenário social, principalmente, para a população de baixa renda que sempre respondeu de forma imediata a qualquer mudança nestes processos. $\mathrm{O}$ mérito da pesquisa é o de ter demonstrado como os efeitos destes processos aparecem na sua diversidade social.

A pesquisa não avaliou apenas a relação desta situação com o mercado de café, mas também o efeito das políticas de diversificação do governo para com outros mercados. Entre os sistemas produtivos pesquisados e seus mercados encontram- 
se os da cana de açúcar, do algodão, do milho e, em fase inicial de expansão, da soja no Paraná. Os dados mostram, de forma detalhada, como tais processos são influenciados por correntes de migração, mas também por estruturas socioétnicas. Isto fica claro no caso da introdução da soja por agricultores do Rio Grande do Sul e Santa Catarina; e no caso da indústria canavieira, que se relaciona basicamente com produtores médios e grandes vindo de São Paulo. Também, faz menção lateral dos fracassos da integração econômica da população cabocla no centro do Paraná, em Campo Mourão, e de outros projetos na vizinhança. Especial destaque ganha a transformação de áreas de produção de alimentos em pastagens no Noroeste da região, onde predomina o Arenito Caiuá.

Tais observações têm, também, em parte, relação com aspectos ecológicos. Conforme o modelo clássico de um estudo regional do tipo alemão, o ambiente ecológico é apresentado no livro como "fundamentos ambientais". Contudo, algumas observações interculturais demonstram certo processo de mestiçagem entre os conceitos aplicados. Primeiro, a geomorfologia brasileira se baseia, em grande parte, no conceito de bacias hidrográficas, destacando os divisores de água, de um lado, e os eixos centrais dos rios, de outro. Contudo, o referido estudo interpreta os rios como fronteiras entre diferentes regiões, seguindo às inspirações de Reinhard Maack na sua "Geografia Física do Paraná". Observa-se que o mesmo critério (rio como fronteira) também foi utilizado no processo de colonização da região, quando os lotes foram alocados entre os espigões, com suas estradas, e os fundos de vale. Desta forma, a pesquisa reproduz um conceito europeu de relevo, e não o conceito latino-americano. Nas pesquisas climáticas, Kohlhepp se refere, em grande parte, a ideias da climatologia brasileira, a qual prefere o conceito das massas de ar (um conceito mais regionalizável), enquanto a climatologia zonal (que dá raiz à classificação de Koeppen) é mais utilizada na Europa. A climatologia europeia, todavia, aparece melhor na descrição da vegetação, sendo apresentada com categorias zonais - novamente, influência dos trabalhos de Reinhard Maack. E finalmente, a avaliação dos solos segue, em grande parte, a tipologia descritiva da Embrapa, que foi essencialmente inspirada na USDA classification e não em classificações genéticas, como é na Alemanha. Assim, uma mistura de diferentes perspectivas entre América Latina e Europa torna-se culturalmente visível na parte do trabalho dedicada a aspectos ecológicos.

As geadas representam um elemento central do trabalho, como tal aspecto ganhou destaque mundial com a grande geada de 1975, que destruiu, de uma vez só, um oitavo da produção mundial. Ao contrário da costumeira visão de que o Brasil teria sido pego de surpresa, as investigações do estudo mostram que o problema era previsível, com antecedência, desde toda a década de 1960. O que aconteceu foi que a política reagiu apenas timidamente através de suas tentativas de diversificação da produção. Nunca se preocupou muito com as possibilidades ecológicas para se evitar a catástrofe, e ainda menos amenizou os efeitos sociais esperáveis. O lucro imediato e rápido, junto à vontade ao poder (Nietzsche) sobre 
o ambiente e a população, levou o país a adotar uma estratégia de colonização que considera - como, depois, também se observou no avanço da frente pioneira na Amazônia - o espaço como objeto colonizável. Neste sentido, a introdução histórica do livro faz muito sentido quando demonstra como o Paraná, como quase todas as regiões do Brasil, até hoje, é refém desta situação. Esta atitude da supremacia colonizadora da política já aparece nas reduções jesuíticas nos séculos XVI e XVII, depois na política dos caminhos reais em conjunto com a exploração de Minas Gerais, no século XVIII, e nas políticas imigratórias do século XIX/XX. Posteriormente ao estudo de Kohlhepp, essa mesma atitude foi seguida por políticas do avanço da frente agrária, na região Amazônica e no Cerrado. Neste sentido, vários de seus alunos têm acompanhado este processo, como Martin Coy, com seu detalhado estudo sobre Rondônia nos anos 1980 (um trabalho importante que ainda espera tradução), e Reinhold Lücker, sobre o Centro-Oeste (este tendo publicações traduzidas, mas sobre a evolução do Alto Uruguai, durante os anos 1980). Integram-se a estes estudos também pesquisas sobre a região do Pantanal, publicados no início deste milênio (Markus Blumenschein e Martina Neuburger, entre outros).

Todos estes estudos - como o livro de Kohlhepp - se caracterizam por um mix singular de métodos quantitativos e qualitativos, o que nos leva a uma última observação. Dentro da discussão epistemológica atual da Geografia parece que a Geografia Regional ganha um novo destaque. Isto mostra as mais recentes reflexões de Rogério Haesbaert (UFF) no Brasil, cuja obra é fortemente influenciada por ideias de Gilles Deleuze e Felix Guattari, como também da geógrafa britânica Doreen Massey. Nestes trabalhos, aparece uma concepção maleável do que é o espaço, inclusive a questão da escala e da diferenciação dos métodos em cada uma delas. Neste sentido, os trabalhos da escola Waibeliana, inclusive as pesquisas de Kohlhepp e Coy, representam - sem destacar o debate teórico - exemplos de trajetos espaço-temporais no sentido de Massey, no seu lado empírico. Captar este "espaço", conceitualmente e metodologicamente, necessita de enorme nitidez empírica, como também de rigidez terminológica, para não se perder em afirmações genéricas quando se apontam aspectos ecológicos, econômicos e sociais. Para isto, se utilizam diferentes representações, desde estatísticas, observações estruturais, entrevistas, interpolações e modulações por diferentes escalas. Neste quesito, o livro aqui resenhado é exemplar.

Infelizmente, as traduções foram feitas sem acompanhamento de um geógrafo acadêmico. Assim, alguns conceitos que são terminologicamente claros para geógrafos, se ofuscam durante o processo da tradução. Por exemplo, povoamentos (Siedlungen) viram "colônias", localizações (Standorte) aparecem como "áreas centrais", estradas (Strassen) como "ruas" e o uso de solo (Bodennutzung) vira "uso de terra", e ainda sistemas de produção (Betriebswirtschaftsformen) tornam-se "gestão de cultivo". Contudo, apesar destes pequenos deslizes, perdoáveis para tradutores que não são da área, a 
tradução se lê de forma extremamente fluida e agradável, até um pouco mais viva do que a linguagem científica extremamente precisa do autor.

Resumidamente, apontamos a enorme riqueza do livro, mesmo que este se apresente apenas 50 anos após sua primeira aparição. A compreensão de processos colonizadores no Brasil, em seus detalhes, é muito mais clara quando se beneficia das concepções não representativas (Thrift, Lorimer) de uma Geografia Regional renovada do que nas concepções da época em que foi escrito. Por isso, a pesquisa mostra - na sua multiperspectividade social, seu detalhismo e sua variedade escalar - um caminho empírico mais do que interessante, com grande valor para a comunidade acadêmica no país.

Endereço para correspondência:

Wolf-DietrichSabr-wolf.sahr@gmail.com

Avenida Coronel Francisco Heráclito dos Santos, 210, Centro Politécnico

81531-970 Curitiba/PR, Brasil 